\title{
A Comparison of Percutaneous Endoscopic Lumbar Discectomy and Open Lumbar Microdiscectomy for Lumbar Disc Herniation in the Korean: A Meta-Analysis
}

\author{
Manyoung Kim $\mathbb{D}^{1},{ }^{1}$ Sol Lee, ${ }^{2}$ Hyeun-Sung Kim, ${ }^{3}$ Sangyoon Park, \\ Sang-Yeup Shim, ${ }^{4}$ and Dong-Ju Lim $\mathbb{1}^{4}{ }^{4}$ \\ ${ }^{1}$ Department of Orthopedic Surgery, Gangnam Nanoori Hospital, 731 Eonju-ro, Gangnam-gu, Seoul 06048, Republic of Korea \\ ${ }^{2}$ Department of Health Policy and Management, Korea University, 145 Anam-ro, Seongbuk-gu, Seoul 02841, Republic of Korea \\ ${ }^{3}$ Department of Neurosurgery, Gangnam Nanoori Hospital, 731 Eonju-ro, Gangnam-gu, Seoul 06048, Republic of Korea \\ ${ }^{4}$ Department of Orthopedic Surgery, Sanggye Paik Hospital, Inje University College of Medicine, 1342 Dongil-ro, Nowon-gu, \\ Seoul 01757, Republic of Korea
}

Correspondence should be addressed to Dong-Ju Lim; scd25@paik.ac.kr

Received 6 June 2018; Accepted 31 July 2018; Published 7 August 2018

Academic Editor: William B. Rodgers

Copyright (C) 2018 Manyoung Kim et al. This is an open access article distributed under the Creative Commons Attribution License, which permits unrestricted use, distribution, and reproduction in any medium, provided the original work is properly cited.

\begin{abstract}
Background. Among the surgical methods for lumbar disc herniation, open lumbar microdiscectomy is considered the gold standard. Recently, percutaneous endoscopic lumbar discectomy is also commonly performed for lumbar disc herniation for its various strong points. Objectives. The present study aims to examine whether percutaneous endoscopic lumbar discectomy and open lumbar microdiscectomy show better results as surgical treatments for lumbar disc herniation in the Korean population. Methods. In the present meta-analysis, papers on Korean patients who underwent open lumbar microdiscectomy and percutaneous endoscopic lumbar discectomy were searched, both of which are surgical methods to treat lumbar disc herniation. The papers from 1973, when percutaneous endoscopic lumbar discectomy was first introduced, to March 2018 were searched at the databases of MEDLINE, EMBASE, PubMed, and Cochrane Library. Results. Seven papers with 1254 patients were selected. A comparison study revealed that percutaneous endoscopic lumbar discectomy had significantly better results than open lumbar microdiscectomy in the visual analogue pain scale at the final follow-up (leg: mean difference $[\mathrm{MD}]=-0.35 ; 95 \%$ confidence interval $[\mathrm{CI}]=-0.61,-0.09$; $\mathrm{p}=0.009$; back: $\mathrm{MD}=-0.79 ; 95 \%$ confidence interval $[\mathrm{CI}]=-1.42,-0.17 ; \mathrm{p}=0.01)$, Oswestry Disability Index $(\mathrm{MD}=-2.12 ; 95 \% \mathrm{CI}=-4.25$, $0.01 ; \mathrm{p}=0.05)$, operation time ( $\mathrm{MD}=-23.06 ; 95 \% \mathrm{CI}=-32.42,-13.70 ; \mathrm{p}<0.00001)$, and hospital stay $(\mathrm{MD}=-4.64 ; 95 \% \mathrm{CI}=-6.37,-2.90$; $\mathrm{p}<0.00001$ ). There were no statistical differences in the MacNab classification (odds ratio $[\mathrm{OR}]=1.02 ; 95 \% \mathrm{CI}=0.71,1.49 ; \mathrm{p}=0.90$ ), complication rate $(\mathrm{OR}=0.72 ; 95 \% \mathrm{CI}=0.20,2.62 ; \mathrm{p}=0.62)$, recurrence rate $(\mathrm{OR}=0.83 ; 95 \% \mathrm{CI}=0.50,1.38 ; \mathrm{p}=0.47)$, and reoperation rate $(\mathrm{OR}=1.45 ; 95 \% \mathrm{CI}=0.89,2.35 ; \mathrm{p}=0.13)$. Limitations. All 7 papers used for the meta-analysis were non-RCTs. Some differences (type of surgery (primary or revisional), treatment options before the operation, follow-up period, etc.) existed depending on the selected paper, and the sample size was small as well. Conclusion. While percutaneous endoscopic lumbar discectomy showed better results than open lumbar microdiscectomy in some items, open lumbar microdiscectomy still showed good clinical results, and it is therefore reckoned that a randomized controlled trial with a large sample size would be required in the future to compare these two surgical methods.
\end{abstract}

\section{Introduction}

Among the surgical methods for lumbar disc herniation, open lumbar microdiscectomy (OLD) is considered the gold standard [1]. Lumbar disc herniation is a common cause of low back pain and radiating pain to the lower extremities [2] and conservative therapy can improve the symptoms in most cases. In 10-20\% of these cases, pain continues despite conservative therapy, and surgical treatment is considered [3]. While OLD can rarely cause scar tissues around nerves, 
damage to facet joints, and lumbar instability after the operation, it is widely performed as it shows good clinical results [4-7].

Recently, percutaneous endoscopic lumbar discectomy (PELD) is also commonly performed for lumbar disc herniation for its various strong points compared to OLD such as surgery under local anesthesia, less damage to surrounding muscles and bone structures, and fast patient recovery [812]. Indications were limited depending on the location and progression of lesions in early days [13, 14], but lately these limitations have been overcome owing to advances in technology and tools [9-12].

Nevertheless, it has not been clearly confirmed whether PELD, which had good results recently, is better than OLD, the gold standard, in Korean patients.

The purpose of this study is to determine through a meta-analysis whether PELD or OLD has better results as a surgical treatment for lumbar disc herniation in the Korean population.

\section{Methods}

2.1. Literature Search Strategy. Relevant studies were searched in MEDLINE, EMBASE, PubMed, and Cochrane Library. Retrieval time was from 1973, when PELD was first introduced, to March 2018. The papers were extracted using search keywords such as "lumbar disc herniation," "microdiscectomy," "percutaneous endoscopic lumbar discectomy," "intervertebral disc displacement," "transforaminal lumbar discectomy," "minimally invasive discectomy," and "interlaminar discectomy"; the researcher extracted only those studies conducted on humans, which were written in English.

2.2. Inclusion Criteria and Exclusion Criteria. Two authors (M Kim and S Lee) identified the titles and abstracts or both and summarized the data from the selected articles. The searched papers were selected based on the following criteria: (1) those which were either randomized or nonrandomized controlled trials, (2) those that had at least one significant result on Korean patients, and (3) those on patients who underwent PELD or OLD for lumbar disc herniation. The papers on those who had a combined surgery and lesions in more than one area and case reports, letters, and comments were excluded.

2.3. Data Extraction. The following data were extracted from the papers collected by two of the authors (M Kim and S Lee): (a) basic information such as the type of trial, follow-up period, type of surgery, sample size, and patient age and sex and (b) clinical results such as the visual analogue pain scale (VAS) score (leg and back), complication rate, recurrence rate, reoperation rate, hospital stay, operation time, $\mathrm{MacNab}$ classification, and Oswestry Disability Index (ODI).

2.4. Quality Assessment. All 7 collected papers were nonrandomized clinical trials, and the Newcastle-Ottawa Quality Assessment Scale (NOQAS) was used for quality assessment. Out of a possible 9 items, 3 of selection, comparability, and exposure or outcome account for 4,2 , and 3 points,

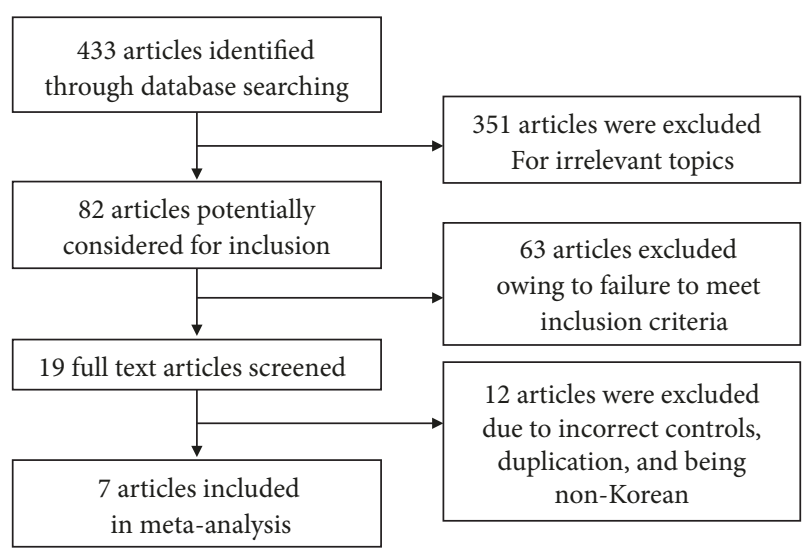

FIgURE 1: Flow diagram detailing study inclusion.

respectively. Five points or more indicated a low risk of bias, while 4 or less indicated having a high risk of bias [15].

2.5. Statistical Analysis. The continuous variables (VAS, hospital stay, operation time, and ODI) were weighted with the number of patients, and the weighted average results were calculated. They were analyzed using standard deviations at a 95\% confidence interval (CI). Meanwhile, the binary variables (complication rate, recurrence rate, reoperation rate, and MacNab score) were analyzed using the odds ratio (OR) at a 95\% CI. I2 statistics were used to determine heterogeneity, and more than $50 \%$ was regarded as heterogeneous. The Review Manager software (version 5.3; The Cochrane Collaboration, Oxford, United Kingdom) was used as a statistical program for analysis.

\section{Result}

3.1. Identification of Relevant Studies. A total of 433 papers were searched, and 426 of them, which did not meet the selection criteria, were excluded. Figure 1 illustrates how the papers were selected, and the final 7 papers satisfied the inclusion criteria and were included in this study's analysis $[11,16-21]$.

3.2. Study Characteristics and Quality Assessment. The basic characteristics of the selected papers are presented in Table 1. All of the 7 selected papers were nonrandomized retrospective studies. The quality assessment results are provided in Table 2, and, except for one paper that scored 4 points in NOQAS, the other papers scored 5-7 points and showed good results in the quality assessment.

\subsection{Meta-Analysis Results}

3.3.1. VAS Score at the Final Follow-Up. Among the 7 papers, 5 presented the results of the VAS (leg), and 293 subjects were included in the analysis: 134 in the PELD group and 159 in the OLD group. The PELD group's average VAS was 2.04 , while that of the OLD group was 2.47. The PELD group showed a significantly lower average VAS (leg) at the final follow-up than the OLD group (mean difference $[\mathrm{MD}]=-0.35$; 
TABLE 1: Baseline characteristics of included studies.

\begin{tabular}{|c|c|c|c|c|c|c|c|}
\hline \multirow[t]{2}{*}{ Author and year } & \multirow[t]{2}{*}{ Study design } & \multicolumn{2}{|c|}{$\begin{array}{c}\text { Number of patients } \\
\text { (male/female) }\end{array}$} & \multicolumn{2}{|c|}{ Patient age (years) } & \multicolumn{2}{|c|}{ Follow-up time (month) } \\
\hline & & PELD & OLD & PELD & OLD & PELD & OLD \\
\hline Jeong (2006) & $\begin{array}{l}\text { Non-randomized } \\
\text { retrospective } \\
\text { comparative } \\
\end{array}$ & $22(14 / 8)$ & $25(16 / 9)$ & $56.45 \pm 10.89$ & $56 \pm 9.12$ & 12 & 12 \\
\hline Lee (2006) & $\begin{array}{l}\text { Non-randomized } \\
\text { retrospective } \\
\text { comparative } \\
\end{array}$ & $30(22 / 8)$ & $30(22 / 8)$ & $39.3(22-67)$ & $39.6(20-64)$ & $38.2(32-45)$ & $36.8(35-42)$ \\
\hline Kim (2007) & $\begin{array}{l}\text { Non-randomized } \\
\text { retrospective } \\
\text { comparative }\end{array}$ & $295(188 / 107)$ & $607(392 / 215)$ & $34.9(13-83)$ & $44.4(17-80)$ & $23.6(18-36)$ & $23.6(18-36)$ \\
\hline Lee (2009) & $\begin{array}{l}\text { Non-randomized } \\
\text { retrospective } \\
\text { comparative } \\
\end{array}$ & $25(16 / 9)$ & $29(22 / 7)$ & $42.0 \pm 11.4$ & $47.7 \pm 12.2$ & $34.0 \pm 4.4$ & $34.3 \pm 4.6$ \\
\hline Ahn (2016) & retrospective cohort & $32(32 / 0)$ & $34(34 / 0)$ & $22.41 \pm 1.68$ & $22.18 \pm 1.51$ & $13.69 \pm 1.26$ & $13.41 \pm 1.02$ \\
\hline Choi (2016) & retrospective cohort & $20(14 / 6)$ & $23(13 / 10)$ & $33.9 \pm 11.1$ & $38 \pm 11.6$ & $27.5 \pm 5.7$ & $27.5 \pm 5.7$ \\
\hline Lee (2017) & $\begin{array}{l}\text { Non-randomized } \\
\text { retrospective } \\
\text { comparative }\end{array}$ & $35(25 / 10)$ & $48(30 / 18)$ & $50.20 \pm 12.87$ & $50.13 \pm 11.56$ & $24.17 \pm 11.83$ & $23.65 \pm 7.94$ \\
\hline
\end{tabular}

TABLE 2: Risk of bias assessment of the nonrandomized studies.

\begin{tabular}{lcccc}
\hline Studies & Selection & Comparability & Exposure & $\begin{array}{c}\text { Total Quality } \\
\text { score }\end{array}$ \\
\hline Jeong (2006) & 2 & 2 & 1 & 5 \\
Lee (2006) & 2 & 2 & 3 & 7 \\
Kim (2007) & 2 & 1 & 1 & 4 \\
Lee (2009) & 2 & 2 & 1 & 5 \\
Lee (2017) & 2 & 2 & 2 & 6 \\
Ahn (2016) & 2 & 2 & 2 & 6 \\
Choi (2016) & 2 & 2 & 1 & 5 \\
\hline
\end{tabular}

95\% CI=-0.61, -0.09; $\mathrm{p}=0.009$ ) (Figure 2). No heterogeneity existed between individual studies included in the analysis $\left(\mathrm{I}^{2}=0 \%, \mathrm{p}=0.91\right)$.

Among the 7 papers, 4 presented the results of the Visual VAS (back), and 246 subjects were included in the analysis: 112 in the PELD group and 134 in the OLD group. The PELD group's average VAS (back) was 2.40, while that of the OLD group was 3.14. The PELD group showed a significantly lower average VAS (back) at the final follow-up than the OLD group ( $\mathrm{MD}=-0.79 ; 95 \% \mathrm{CI}=-1.42,-0.17 ; \mathrm{p}=0.01$ ) (Figure 3 ). Heterogeneity existed between individual studies included in the analysis $\left(\mathrm{I}^{2}=85 \%, \mathrm{p}=0.0001\right)$.

3.3.2. MacNab Classification at the Final Follow-Up. Among the 7 papers, 3 presented the results of the MacNab score (success rate), and 1,009 subjects were included in the analysis: 347 in the PELD group and 662 in the OLD group. Those who answered with excellent or good were defined as successful, and 298 among the 347 subjects in the PELD group answered with successful in the MacNab criteria. Among the 662 subjects in the OLD group, 564 answered with successful. There were no significant differences in the average MacNab score (success rate) between the PELD and OLD groups (odds ratio $[\mathrm{OR}]=1.02 ; 95 \% \mathrm{CI}=0.71,1.49 ; \mathrm{p}=0.90$ ) (Figure 4 ). There was no heterogeneity between individual studies included in the analysis $\left(\mathrm{I}^{2}=0 \%, \mathrm{p}=0.72\right)$.

3.3.3. ODI. Among the 7 papers, 4 presented the results of the ODI, and 246 subjects were included in the analysis: 112 in the PELD group and 134 in the OLD group. The PELD group's average ODI was $14.54 \%$, while that of the OLD group was $16.52 \%$. The PELD group showed a significantly lower average $\mathrm{ODI}$ at the final follow-up than the OLD group $(\mathrm{MD}=-2.12$; $95 \% \mathrm{CI}=-4.25,0.01 ; \mathrm{p}=0.05$ ) (Figure 5). Heterogeneity existed between individual studies included in the analysis $\left(\mathrm{I}^{2}=67 \%\right.$, $\mathrm{p}=0.03)$.

3.3.4. Complication Rate. Among the 7 papers, 4 presented the results of the complication rate, and 1,105 subjects were included in the analysis: 387 in the PELD group and 718 in the OLD group. Fourteen subjects in the PELD group and 26 subjects in the OLD group had complications. There were no significant differences in the complication rate between the PELD and OLD groups $(\mathrm{OR}=0.72 ; 95 \% \mathrm{CI}=0.20,2.62$; 


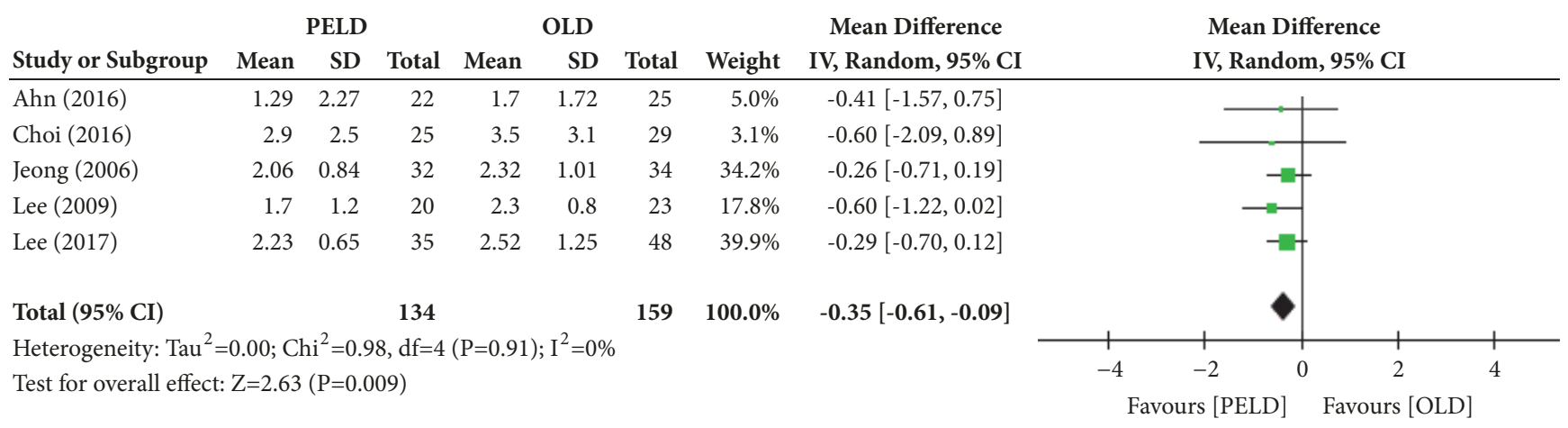

FIgURE 2: Forest plot of comparison: PELD versus OLD; outcome: 1-1 for VAS (leg), final follow-up.

\begin{tabular}{|c|c|c|c|c|c|c|c|c|c|c|c|c|}
\hline \multirow[b]{2}{*}{ Study or Subgroup } & \multicolumn{3}{|c|}{ PELD } & \multicolumn{3}{|c|}{ OLD } & \multicolumn{3}{|c|}{ Mean Difference } & \multirow{2}{*}{\multicolumn{2}{|c|}{$\begin{array}{c}\text { Mean Difference } \\
\text { IV, Random, 95\% CI }\end{array}$}} & \\
\hline & Mean & SD & Total & Mean & SD & Total & Weight & IV, Random, 95\% CI & & & & \\
\hline Ahn (2016) & 2.5 & 0.62 & 32 & 2.91 & 0.67 & 34 & $30.1 \%$ & $-0.41[-1.57,0.75]$ & & --1 & & \\
\hline Choi (2016) & 2 & 0.6 & 20 & 3.7 & 1 & 23 & $27.2 \%$ & $-0.60[-2.09,0.89]$ & & $\rightarrow-$ & & \\
\hline Lee (2009) & 2.9 & 2.4 & 25 & 3.1 & 2.5 & 29 & $13.5 \%$ & $-0.20[-1.51,1.11]$ & & & & \\
\hline Lee (2017) & 2.23 & 0.65 & 35 & 2.85 & 1.09 & 48 & $29.2 \%$ & $-0.62[-1.00,-0.24]$ & & $-\infty$ & & \\
\hline Total $(95 \%$ CI $)$ & & & 112 & & & 134 & $100.0 \%$ & $-0.79[-1.42,-0.17]$ & & & & \\
\hline \multicolumn{9}{|c|}{ Heterogeneity: $\mathrm{Tau}^{2}=0.31 ; \mathrm{Chi}^{2}=20.31, \mathrm{df}=3(\mathrm{P}=0.0001) ; \mathrm{I}^{2}=85 \%$} & -4 & -2 & 2 & 4 \\
\hline
\end{tabular}

FIgURE 3: Forest plot of comparison: PELD versus OLD; outcome: 1-2 for VAS (back), final follow-up.

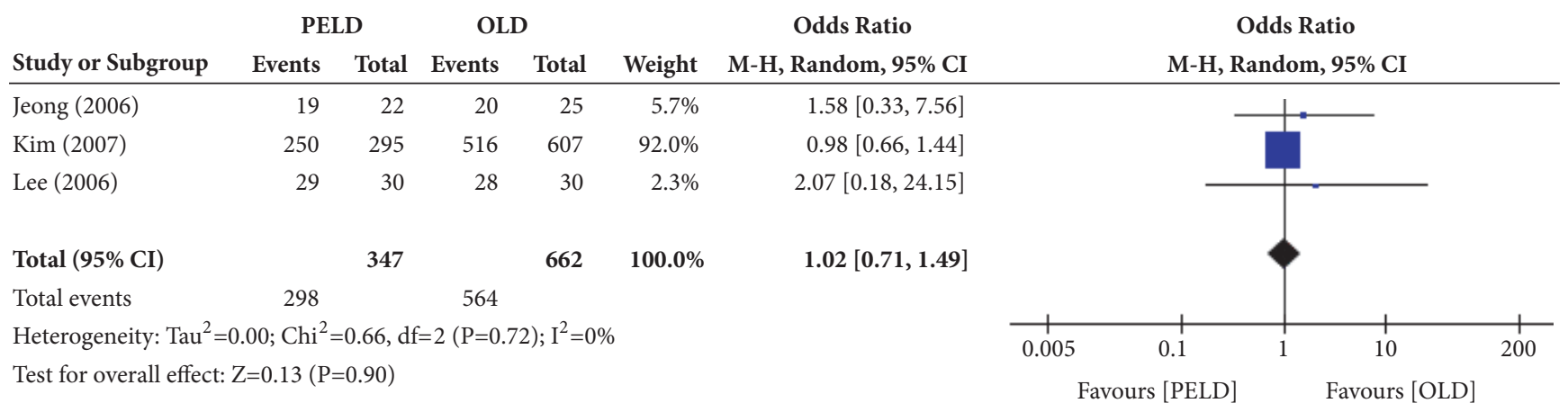

FIgURE 4: Forest plot of comparison: PELD versus OLD, outcome: 2 for MacNab classification (success rate).

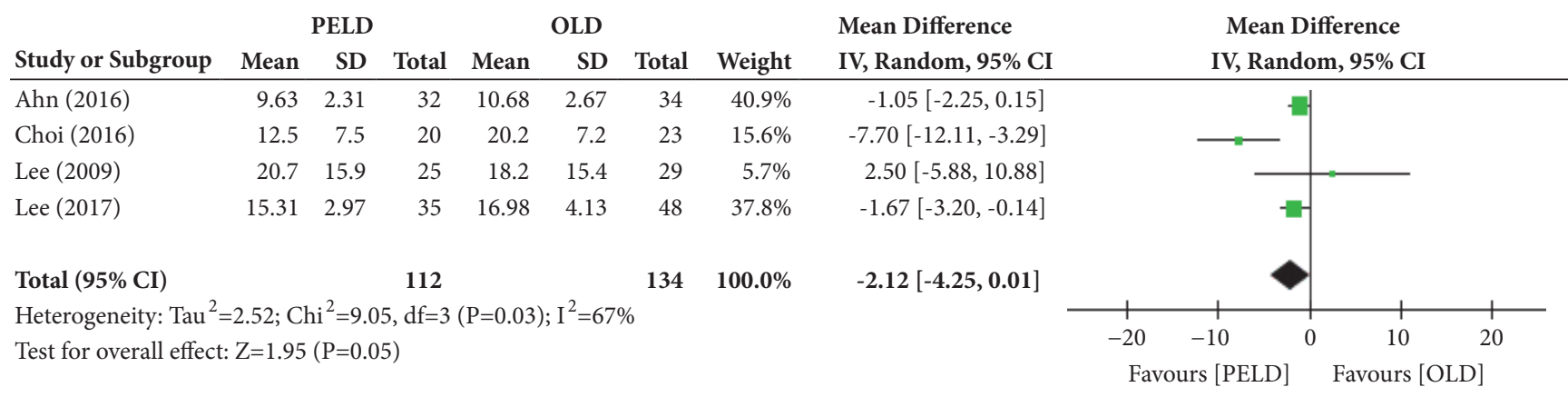

FIGURE 5: Forest plot of comparison: PELD versus OLD; outcome: 3 for ODI, final follow-up. 
PELD

OLD

Odds Ratio

Odds Ratio

Study or Subgroup Events Total Events Total Weight M-H, Random, 95\% CI

$1.07[0.24,4.70]$

Ahn (2016)

$\begin{array}{lllll}4 & 32 & 4 & 34 & 29.1 \%\end{array}$

$1.88[0.76,4.67]$

Lee (2009)

$9 \quad 295$

$10 \quad 607$

$38.1 \%$

$0.36[0.04,3.71]$

Lee (2017)

125

$3 \quad 29$

$18.6 \%$

$0.06[0.00,1.04]$

Total $(95 \% \mathrm{CI})$

387

$14.1 \%$

Total events

$718 \quad 100.0 \%$

$0.72[0.20,2.62]$

Heterogeneity: $\mathrm{Tau}^{2}=0.93 ; \mathrm{Chi}^{2}=6.92, \mathrm{df}=3(\mathrm{P}=0.07) ; \mathrm{I}^{2}=57 \%$

Test for overall effect: $\mathrm{Z}=0.50(\mathrm{P}=0.62)$

FIgURE 6: Forest plot of comparison: PELD versus OLD; outcome: 4 for complication rate.

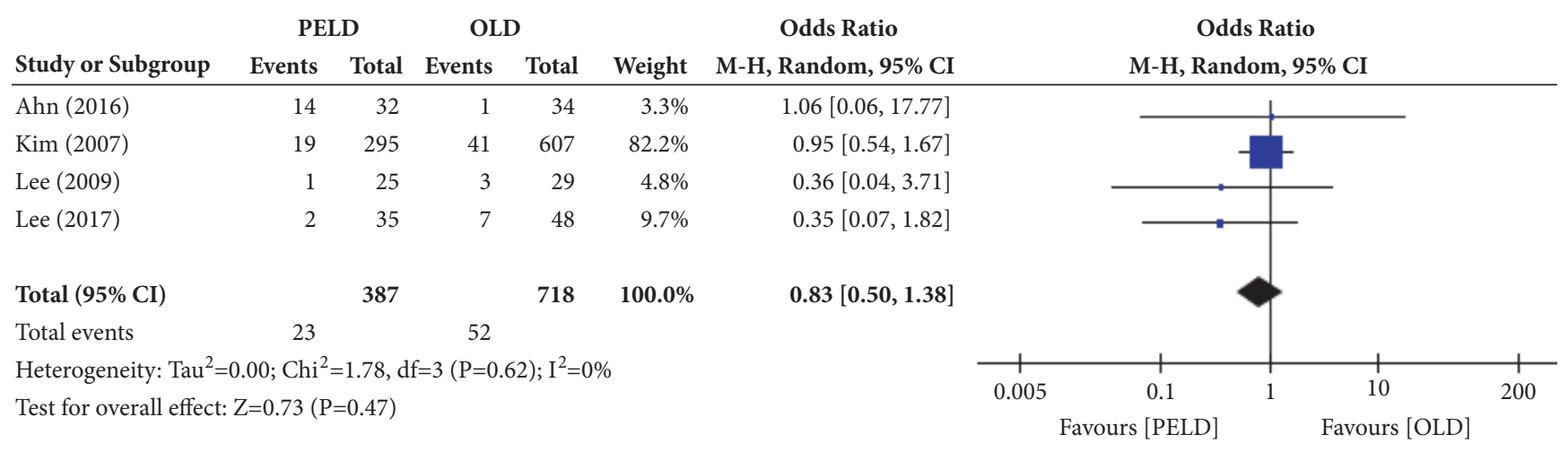

FIGURE 7: Forest plot of comparison: PELD versus OLD; outcome: 5 for recurrence rate.

$\mathrm{p}=0.62$ ) (Figure 6). Heterogeneity existed between individual studies included in the analysis $\left(\mathrm{I}^{2}=57 \%, \mathrm{p}=0.07\right)$.

3.3.5. Recurrence Rate. Among the 7 papers, 4 presented the results of the recurrence rate, and 1,105 subjects were included in the analysis: 387 in the PELD group and 718 in the OLD group. Twenty-three subjects in the PELD group and 52 in the OLD group had recurrence. There were no statistically significant differences in the recurrence rate between the PELD and OLD groups $(\mathrm{OR}=0.83 ; 95 \% \mathrm{CI}=0.50,1.38 ; \mathrm{p}=0.47)$ (Figure 7 ). There was no heterogeneity between individual studies included in the analysis $\left(\mathrm{I}^{2}=0 \%, \mathrm{p}=0.62\right)$.

3.3.6. Reoperation Rate. Among the 7 papers, 4 presented the results of the reoperation rate, and 1,065 subjects were included in the analysis: 372 in the PELD group and 693 in the OLD group. Thirty-one subjects in the PELD group and 43 subjects in the OLD group had reoperation. There were no significant differences in the reoperation rate between the PELD and OLD groups $(\mathrm{OR}=1.45 ; 95 \% \mathrm{CI}=0.89,2.35 ; \mathrm{p}=0.13$ ) (Figure 8 ). There was no heterogeneity between individual studies included in the analysis $\left(\mathrm{I}^{2}=0 \%, \mathrm{p}=0.49\right)$.

3.3.7. Operation Time. Among the 7 papers, 6 presented the results of operation time, and 1,172 subjects were included in the analysis: 424 in the PELD group and 748 in the OLD group. The PELD group's average operation time was $55.84 \mathrm{~min}$, and that of the OLD group was $83.99 \mathrm{~min}$.
The PELD group's average operation time was significantly shorter than that of the OLD group $(\mathrm{MD}=-23.06$; $95 \% \mathrm{CI}=-$ $32.42,-13.70 ; \mathrm{p}<0.00001$ ) (Figure 9). Heterogeneity existed between individual studies included in the analysis $\left(\mathrm{I}^{2}=91 \%\right.$, $\mathrm{p}<0.00001)$.

3.3.8. Hospital Stay. Among the 7 papers, 5 presented the results of hospital stay, and 270 subjects were included in the analysis: 129 in the PELD group and 141 in the OLD group. The PELD group's average hospital stay was 2.69 days, and that of the OLD group was 7.47 days. The PELD group's average hospital stay was significantly shorter than that of the OLD group $(\mathrm{MD}=-4.64 ; 95 \% \mathrm{CI}=-6.37,-2.90 ; \mathrm{p}<0.00001)$ (Figure 10). Heterogeneity existed between individual studies included in the analysis $\left(\mathrm{I}^{2}=92 \%, \mathrm{p}<0.00001\right)$.

\section{Discussion}

In general, OLD has been mostly performed as a surgical treatment for lumbar disc herniation. This technique could possibly lead to lumbar instability and iatrogenic injury as it requires the removal of some posterior structures such as lamina, ligament flavum, and facet joints, dissection of muscles near the spine, and pulling of nerve branches [22, 23]. In response, PELD, which had relatively smaller loss of posterior structures and faster early recovery, was introduced by Kambin and Gellman [24] and is recently used widely for its strength where it can be performed under local 
PELD OLD

Odds Ratio

Odds Ratio

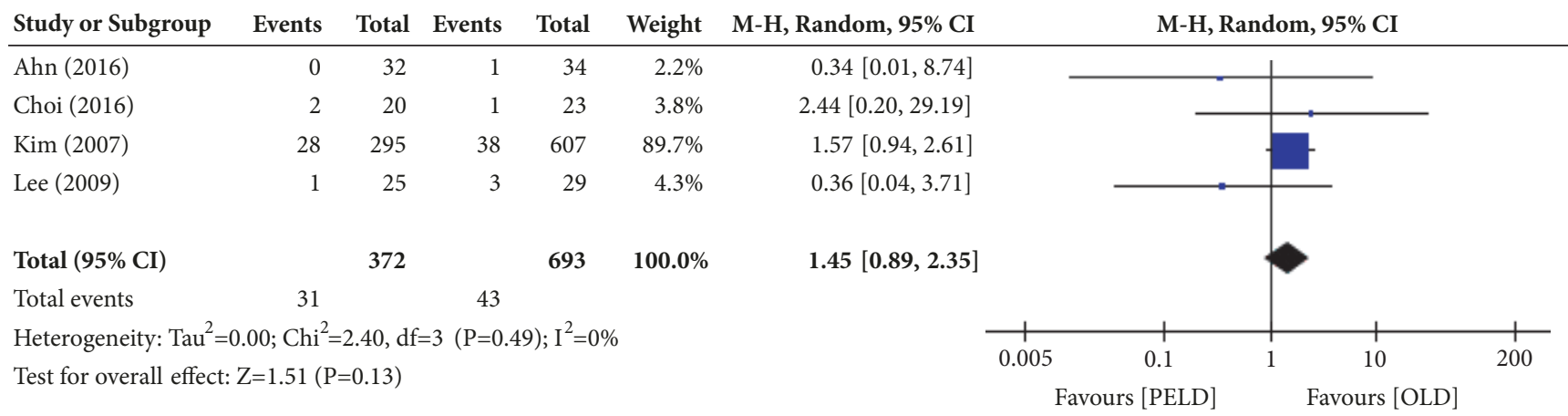

FIgURE 8: Forest plot of comparison: PELD versus OLD; outcome: 6 for reoperation rate.

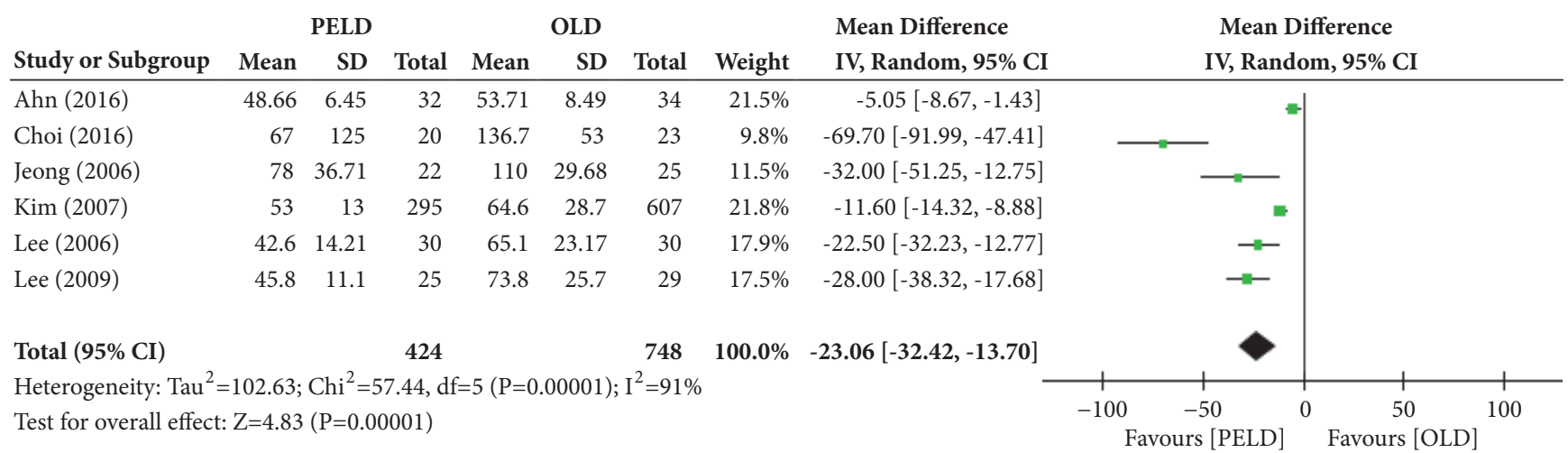

FIgURE 9: Forest plot of comparison: PELD versus OLD; outcome: 7 for operation (minute).

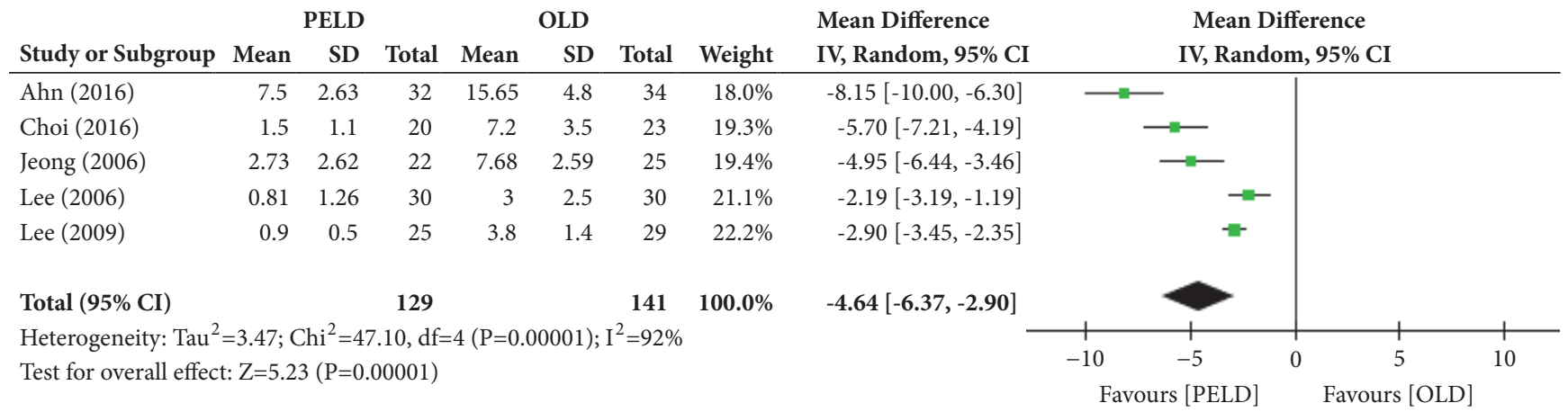

FIgURE 10: Forest plot of comparison: PELD versus OLD; outcome: 8 for hospital stay (days).

anesthesia [25]. However, PELD also has its downsides; that is, it insufficiently removes the disc, has a high recurrence rate, and requires a certain period of time to develop skill proficiency [26-28], and therefore it calls for a comparison of these two surgical methods for their stability and effect.

Recently, a meta-analysis, which compared OLD and PELD as surgical treatments for lumbar disc herniation, reported two cases in 2016 [29, 30]. Each meta-analysis was performed by extracting data from 7 papers; the papers were limited to those published after 2000, when endoscopic technology and tools were advanced, and as a result each one selected 5 and 6 papers. The studies conducted on Koreans patients accounted for a majority with 3 and 4 papers.
Considering this could work as a bias, this study performed a meta-analysis only on those conducted on Korean patients.

In the present study, PELD showed statistically significantly better results than OLD in the VAS score (of both leg and back) at the final follow-up, ODI, operation time, and hospital stay. We believe it is especially meaningful that contrary to previous meta-analysis studies [29, 30] PELD showed better results in the VAS score as it is the primary outcome of the surgery. In previous meta-analysis studies $[29,30]$, PELD showed better results in operation time and hospital stay in both and this study, whereas PELD showed better results in the ODI in one of the two previous metaanalysis studies [29] and this study. PELD showed statistically 
significantly better results in more items in this study than in previous studies. It is because endoscopic surgery has less damage to muscles and structures around the spine as well-known [31, 32]. In addition, we believe that the papers included in this study are relatively recent researches with the enough development of endoscopic instruments and proficiency of endoscopic skills.

The MacNab classification was recorded in only 3 among the 7 papers, and there were no significant differences between the two surgical methods. At the final follow-up, both surgical methods showed successful results. So, we have determined that both methods are effective.

In this study, there were no significant differences in reoperation and recurrence rate. There were two previous reports stating that there were no differences between the two surgical methods $[14,33]$ and there was another report that PELD had more recurrence and reoperation rate [26]. Usually, in such cases, there was a remaining disc piece or it was accompanied by stenosis due to reoperation and recurrence [34], and it would be important to determine appropriate indications as well as develop the proficiency of surgical skills.

Complications included infection, spinal cord injury, cerebrospinal fluid leak, damage to nerve roots, and postoperative sensory abnormalities [11, 16, 19, 20]. A previous report stated that PELD had fewer complications, thanks to the development of tools such as the camera system [35], but another reported that it would do more damage to the spinal cord and nerve roots due to a lack of depth [36]. In this study, each paper showed different results, and there were no statistically significant differences.

This study has some limitations. All 7 papers used for the meta-analysis were nonrandomized trials, and there was selection bias as a result. The quality of these trials was also fairly high. In addition, clinical heterogeneity existed in this study. Type of surgery (primary or revisional), surgical indications, treatment options before the operation, and followup period during the symptom period varied depending on the selected paper, and the sample size was small as well. Particularly revision surgery may demand different approachrelated surgical technique and more operation time. They may be subject to more complications that do not exist during the initial surgery. Finally, a physician's proficiency makes a huge difference in PELD, and it is believed that the difference in physicians in each paper would have worked as a bias.

\section{Conclusion}

This meta-analysis found that PELD had significantly better results than OLD in the VAS score, ODI, operation time, and hospital stay as a surgical treatment for lumbar disc herniation in the Korean population. Nevertheless, OLD still showed good clinical results, and therefore a randomized controlled study with a large sample size would be required in the future to compare these two surgical methods.

\section{Conflicts of Interest}

The authors declare that they have no conflicts of interest.

\section{References}

[1] P. J. Apostolides, R. Jacobowitz, and V. K. Sonntag, "Lumbar discectomy microdiscectomy: "the gold standard".," Clinical Neurosurgery, vol. 43, pp. 228-238, 1996.

[2] P. Campbell, G. Wynne-Jones, S. Muller, and K. M. Dunn, "The influence of employment social support for risk and prognosis in nonspecific back pain: a systematic review and critical synthesis," International Archives of Occupational and Environmental Health, vol. 86, no. 2, pp. 119-137, 2013.

[3] O. P. Gautschi, D. Cadosch, and G. Hildebrandt, "Acute low back pain-assessment and management," Praxis, vol. 97, no. 2, pp. 58-68, 2008.

[4] P. D. Angevine and P. C. McCormick, "Outcomes research and lumbar discectomy.," Neurosurgical Focus, vol. 13, no. 2, p. E8, 2002.

[5] R. A. Davis, "A long-term outcome analysis of 984 surgically treated herniated lumbar discs," Journal of Neurosurgery, vol. 80, no. 3, pp. 415-421, 1994.

[6] R. Casal-Moro, M. Castro-Menéndez, M. Hernández-Blanco, J. A. Bravo-Ricoy, and F. J. Jorge-Barreiro, "Long-term outcome after microendoscopic diskectomy for lumbar disk herniation: a prospective clinical study with a 5-year follow-up," Neurosurgery, vol. 68, no. 6, pp. 1568-1575, 2011.

[7] M. Wenger, L. Mariani, A. Kalbarczyk, and U. Gröger, "Longterm outcome of 104 patients after lumbar sequestrectomy according to Williams," Neurosurgery, vol. 49, no. 2, pp. 329335,2001

[8] J. N. A. Gibson, J. G. Cowie, and M. Iprenburg, "Transforaminal endoscopic spinal surgery: the future 'gold standard' for discectomy? - a review," The Surgeon, vol. 10, no. 5, pp. 290-296, 2012.

[9] A. T. Yeung and P. M. Tsou, "Posterolateral endoscopic excision for lumbar disc herniation: surgical technique, outcome, and complications in 307 consecutive cases," The Spine Journal, vol. 27, no. 7, pp. 722-731, 2002.

[10] Y. Ahn, S.-H. Lee, W.-M. Park, H.-Y. Lee, S.-W. Shin, and H.-Y. Kang, "Percutaneous endoscopic lumbar discectomy for recurrent disc herniation: surgical technique, outcome, and prognostic factors of 43 consecutive cases," The Spine Journal, vol. 29, no. 16, pp. E326-332, 2004.

[11] D. Y. Lee, C. S. Shim, Y. Ahn, Y.-G. Choi, H. J. Kim, and S.-H. Lee, "Comparison of percutaneous endoscopic lumbar discectomy and open lumbar microdiscectomy for recurrent disc herniation," Journal of Korean Neurosurgical Society, vol. 46, no. 6, pp. 515-521, 2009.

[12] S. Ruetten, M. Komp, H. Merk, and G. Godolias, "Recurrent lumbar disc herniation after conventional discectomy: a prospective, randomized study comparing full-endoscopic interlaminar and transforaminal versus microsurgical revision," Journal of Spinal Disorders \& Techniques, vol. 22, no. 2, pp. 122129, 2009.

[13] D. A. Ditsworth, "Endoscopic transforaminal lumbar discectomy and reconfiguration: A posterolateral approach into the spinal canal," World Neurosurgery, vol. 49, no. 6, pp. 588-598, 1998.

[14] J. L. Schaffer and P. Kambin, "Percutaneous posterolateral lumbar discectomy and decompression with a 6.9-millimeter cannula: analysis of operative failures and complications," The Journal of Bone \& Joint Surgery, vol. 73, no. 6, pp. 822-831, 1991. 
[15] A. Stang, "Critical evaluation of the Newcastle-Ottawa scale for the assessment of the quality of nonrandomized studies in metaanalyses," European Journal of Epidemiology, vol. 25, no. 9, pp. 603-605, 2010.

[16] S. S. Ahn, S. H. Kim, D. W. Kim, and B. H. Lee, "Comparison of outcomes of percutaneous endoscopic lumbar discectomy and open lumbar microdiscectomy for young adults: a retrospective matched cohort study," World Neurosurgery, vol. 86, pp. 250258, 2016.

[17] K.-C. Choi, J.-S. Kim, and C.-K. Park, "Percutaneous endoscopic lumbar discectomy as an alternative to open lumbar microdiscectomy for large lumbar disc herniation," Pain Physician, vol. 19, no. 2, pp. E291-E300, 2016.

[18] J. S. Jeong, S. H. Lee, S. J. Lee, and B. W. Hwang, "The Clinical Comparison between Open Surgery and Percutaneous Endoscopic Lumbar Discectomy in Extraforaminal Lumbar Disc Herniation," Journal of Korean Neurosurgical Society, vol. 39, no. 6, pp. 413-418, 2006.

[19] M.-J. Kim, S.-H. Lee, E.-S. Jung et al., “Targeted percutaneous transforaminal endoscopic diskectomy in 295 patients: comparison with results of microscopic diskectomy," World Neurosurgery, vol. 68, no. 6, pp. 623-631, 2007.

[20] J. Lee, H. Kim, Y. Pee, J. Jang, and I. Jang, "Comparison of Percutaneous Endoscopic Lumbar Diskectomy and Open Lumbar Microdiskectomy for Recurrent Lumbar Disk Herniation," Journal of Neurological Surgery Part A: Central European Neurosurgery, 2017.

[21] S.-H. Lee, S.-E. Chung, Y. Ahn, T.-H. Kim, J.-Y. Park, and S.W. Shin, "Comparative radiologic evaluation of percutaneous endoscopic lumbar discectomy and open microdiscectomy: a matched cohort analysis," Mount Sinai Journal of Medicine, vol. 73, no. 5, pp. 795-801, 2006.

[22] I. Thongtrangan, H. Le, J. Park, and D. H. Kim, "Minimally invasive spinal surgery: a historical perspective.," Neurosurgical Focus, vol. 16, no. 1, p. E13, 2004.

[23] G. Xin, H. Shi-Sheng, and Z. Hai-Long, "Morphometric analysis of the YESS and TESSYS techniques of percutaneous transforaminal endoscopic lumbar discectomy," Clinical Anatomy, vol. 26, no. 6, pp. 728-734, 2013.

[24] G. P. Jasper, G. M. Francisco, and A. E. Telfeian, "Endoscopic transforaminal discectomy for an extruded lumbar disc herniation," Pain Physician, vol. 16, no. 1, pp. E31-E35, 2013.

[25] G. Choi, S.-H. Lee, P. P. Raiturker, S. Lee, and Y.-S. Chae, "Percutaneous endoscopic interlaminar discectomy for intracanalicular disc herniations at L5-S1 using a rigid working channel endoscope," Neurosurgery, vol. 58, no. 1, pp. ONS-59ONS-68, 2006.

[26] J. Cheng, H. Wang, W. Zheng et al., "Reoperation after lumbar disc surgery in two hundred and seven patients," International Orthopaedics, vol. 37, no. 8, pp. 1511-1517, 2013.

[27] H. Wang, B. Huang, C. Li et al., "Learning curve for percutaneous endoscopic lumbar discectomy depending on the surgeon's training level of minimally invasive spine surgery," Clinical Neurology and Neurosurgery, vol. 115, no. 10, pp. 19871991, 2013.

[28] Y. Ahn, C.-H. Kim, J. H. Lee, S.-H. Lee, and J.-S. Kim, "Radiation exposure to the surgeon during percutaneous endoscopic lumbar discectomy: A prospective study," The Spine Journal, vol. 38, no. 7, pp. 617-625, 2013.

[29] X. Li, Y. Han, Z. Di et al., "Percutaneous endoscopic lumbar discectomy for lumbar disc herniation," Journal of Clinical Neuroscience, vol. 33, pp. 19-27, 2016.
[30] W. Ruan, F. Feng, Z. Liu, J. Xie, L. Cai, and A. Ping, "Comparison of percutaneous endoscopic lumbar discectomy versus open lumbar microdiscectomy for lumbar disc herniation: A metaanalysis," International Journal of Surgery, vol. 31, pp. 86-92, 2016.

[31] H. M. Mayer and M. Brock, "Percutaneous endoscopic lumbar discectomy (PELD)," Neuro Surgical Review, vol. 16, no. 2, pp. 115-120, 1993.

[32] S. Tenenbaum, H. Arzi, A. Herman et al., "Percutaneous Posterolateral Transforaminal Endoscopic Discectomy: Clinical Outcome, Complications, and Learning Curve Evaluation," Surgical Technology International, vol. 21, pp. 278-283, 2011.

[33] H. J. Goald, "Microlumbar discectomy: Follow-up of 477 patients," Microsurgery, vol. 2, no. 2, pp. 95-100, 1980.

[34] P. Kambin, "Arthroscopic microdiscectomy," Arthroscopy: The Journal of Arthroscopic and Related Surgery, vol. 8, no. 3, pp. 287295, 1992.

[35] S. Ruetten, M. Komp, H. Merk, and G. Godolias, "Surgical treatment for lumbar lateral recess stenosis with the full-endoscopic interlaminar approach versus conventional microsurgical technique: A prospective, randomized, controlled study - Clinical article," Journal of Neurosurgery: Spine, vol. 10, no. 5, pp. 476485, 2009.

[36] O. Righesso, A. Falavigna, and O. Avanzi, "Comparison of open discectomy with microendoscopic discectomy in lumbar disc herniations: results of a randomized controlled trial," Neurosurgery, vol. 61, no. 3, pp. 545-549, 2007. 


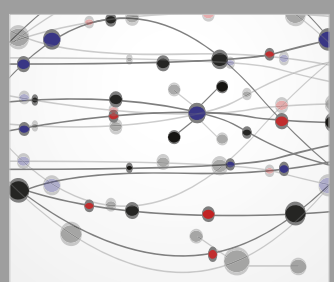

The Scientific World Journal
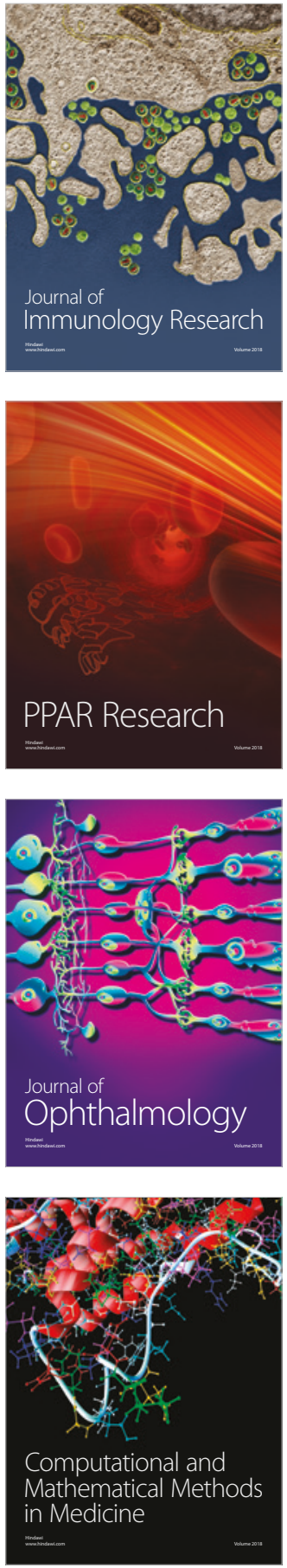

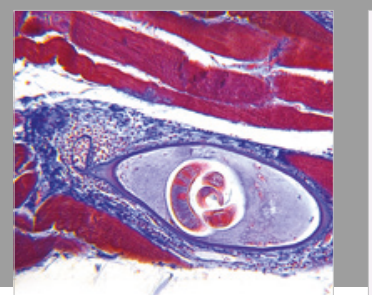

Gastroenterology Research and Practice

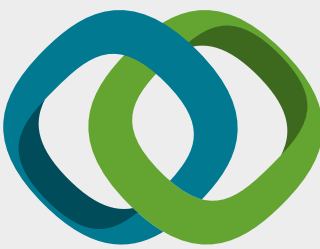

\section{Hindawi}

Submit your manuscripts at

www.hindawi.com
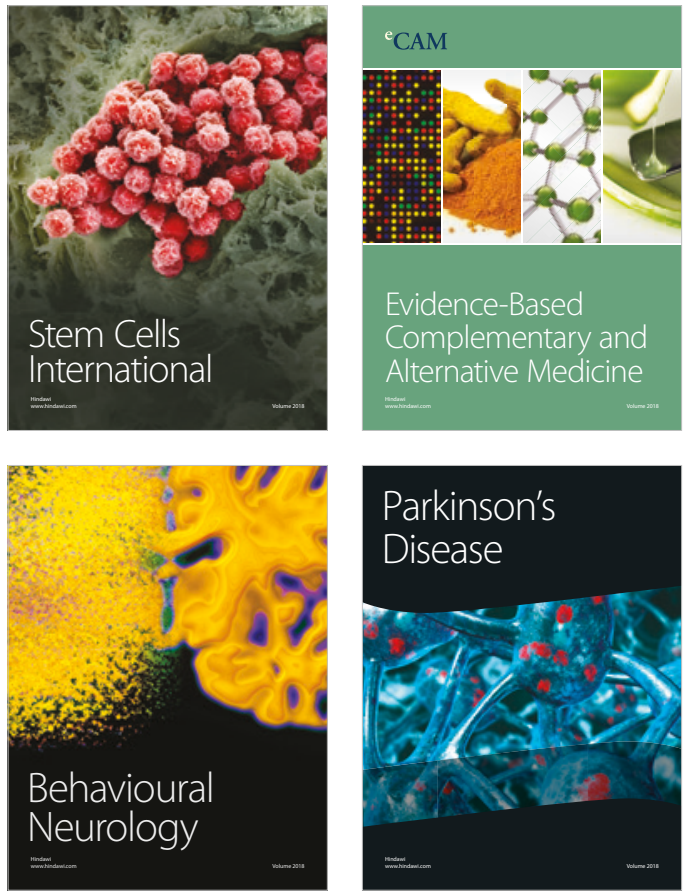

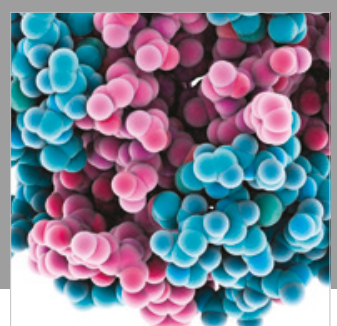

ournal of

Diabetes Research

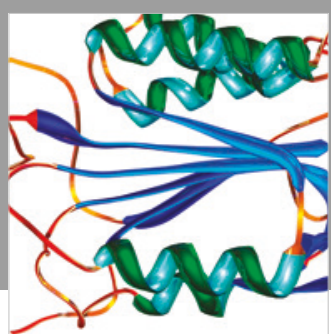

Disease Markers
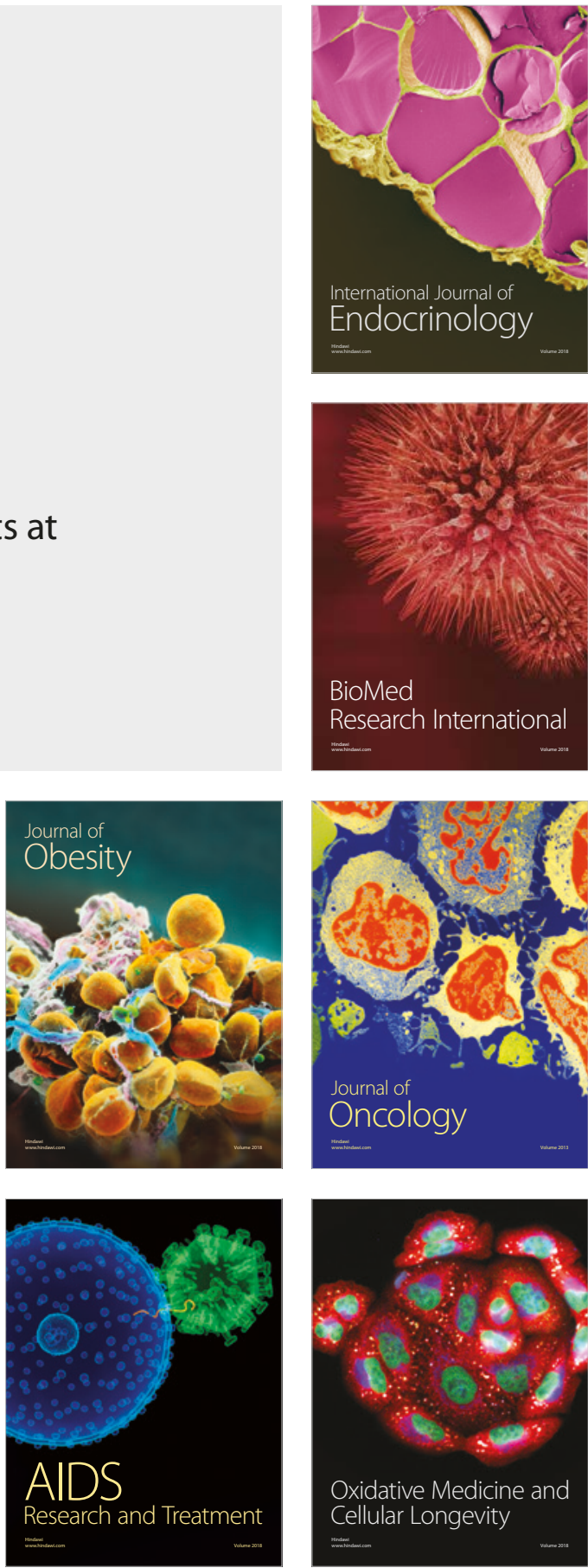